\title{
Expression, Purification and Evaluation of Antigenicity of CagA Antigenic Fragment of Helicobacter pylori
}

\author{
Vahideh Farjadi ${ }^{1}$, Hamid Abtahi ${ }^{2,}$, Mohammad Reza Zolfaghari ${ }^{1}$, Safieh Soufian ${ }^{3}$, Leila \\ Hasanzadeh $^{4}$ \\ ${ }^{1}$ Department of Microbiology, Faculty of Science, Islamic Azad University, Qom Branch, Qom, IR Iran \\ ${ }_{2}^{2}$ Molecular and Medicine Research Center, Arak University of Medical Sciences, Arak, IR Iran \\ ${ }^{3}$ Department of Biology, Payame Noor University, Arak, IR Iran \\ ${ }^{4}$ Department of Biotechnology and Microbiology, Arak University of Medical Sciences, Arak, IR Iran \\ ${ }^{*}$ Corresponding author: Hamid Abtahi, Molecular and Medicine Research Center, Arak University of Medical Sciences, Arak, IR Iran. Tel: +98-8614173502. Fax:+98-8614173526. E-mail: \\ abtahi@arakmu.ac.ir.
}

Received: July 22, 2012; Revised: December 8, 2012; Accepted: January 12, 2013

\begin{abstract}
Background: Helicobacter pylori is a human pathogen that causes chronic gastritis, which playsrole in gastric and duodenal ulcers, is also involved in gastric carcinogenesis and may be regarded as a possible important factor in at least a subset of patients with functional dyspepsia.

Objectives: This study was aimed to construct a recombinant protein containing $H$. pylori antigenic CagA region and determine its antigenicity as a vaccine candidate against $H$. pylori.

Meterials and Methods: The antigenic region of CagA gene was detected by bioinformatics techniques. In this study, the H.pylori antigenic CagA region was amplified by PCRand sub-cloned to prokaryotic expression vector pET32a. Escherichia coli BL21(DE3) pLysS was transformed with pET32a- CagA and gene expression was induced by IPTG. The expressed protein was purified by affinity chromatography using NiNTA resin. The integrity of the product was confirmed by western-blot analysis using Sera of infected individual. Finally antigenicity was studied by western-blot analysis using human sera infected with $H$. pylori.

Results: Enzyme digestion analysis, PCR and sequencing showed that the target gene (1245 bp)was correctly inserted into the recombinant vector. The expressed protein was purified using affinity chromatography by Ni-NTA resin. The data also indicated that CagA protein from H. pylori detected from patients' sera.

Conclusions: Results indicates that antigenic region of recombinant CagA protein were recognized as an antigen, so it might be a candidate for the development of H. pylori vaccine, ELISA kit designs and serological diagnosis of H. pylori infections.
\end{abstract}

Keywords: Antigenic Region; Antigenicity; Cytotoxin-Associated Gene (cagA); Helicobacter pylori

\section{Background}

Helicobacter pylori is a Gram negative, microaerophilic spiral bacterium that colonizes in the human stomach and induces gastric mucosal inflammations that are linked to severe gastritis-associated diseases including atrophic gastritis, peptic ulcer and gastric cancer (1). $H$. pylori is detected in half of the world's population. In 1994, the World Health Organization and International Agency for Research on Cancer categorized H. pylori infection as a group I carcinogens (2). An important virulence factor of $H$. pylori is a secreted toxin known as Cytotoxinassociated gene $\mathrm{A}(\mathrm{CagA})$ which is located at the end of an approximately $40-\mathrm{kb}$ cluster of genes called cag pathogenicity island (PAI).

Cag PAI encodes a type-IV secretion system (3) and transfers CagA protein into the intracellular region of gastric epithelial cell, inducing cellular hyper proliferation, apoptosis and leading to failure of gastric epithelial cell in maintaining its normal cytoskeletal structure (4), Also increases the secretion of cytokines such as tumor necrosis factor (TNF) and interleukin (IL) 1, 6 and 8 by the epithelial cells. The IL- 8 leads to intense inflammatory responses and stimulates the production of oxygen free radicals that could cause DNA damage to adjacent cells. Accumulation of oxidative DNA damage could lead to genetic modifications of gastric epithelial cells which are carcinogenic (5). A large number of studies have proven the association between CagA positive strains and gastritis and peptic ulcer. Also it may induce the persistent systemic inflammatory responses and the increased risk of recurrent atherosclerotic events (6).

Implication for health policy/practice/research/medical education:

Currently, the main treatment to eliminate H. pylori is combined antibiotics therapy. However, due to incomplete eradication of $H$. pylori through antibiotic treatment, the cost of combination therapy, re-infection, patients' complaints and emerges of antibiotic resistance strains, vaccination could be suggested as a preventive approach. The CagA has been approved as an effective virulence factor involved in the pathogenesis of $H$. pylori infection. Thus, this protein can be considered as a vaccine candidate.

Copyright (C) 2013, Ahvaz JundishapurUniversity of Medical Sciences; Published by Kowsar Corp. This is an open-access article distributed under the terms of the Creative Commons Attribution License, which permits unrestricted use, distribution, and reproduction in any medium, provided the original work is properly cited. 


\section{Objectives}

By using major epitopes of each antigen instead of the whole antigen, the specificity of fragment will increase and more specific immune responses are stimulated. Isolation, characterization and expression of $H$. pylori antigenic region of CagA ( $\operatorname{arCagA}$ ) gene in E. coli as a host, was presented in this paper. We also showed that recombinant CagA protein was recognized by infected human sera using Western blot analysis.

\section{Materials and Methods}

\subsection{Strains, Plasmids, Media and Sera}

E. coli strain DH5 $\alpha$ (Strata gene) ( $f$ - gyr A96 Nalr, recA1 relA1 Thi-1 hsdR17 $r-k m+k$ ) were used for initial cloning and maintenance of different DNA fragments. To produce the recombinant protein, prokaryotic expression vector pET32a (Novagene) was used. This vector can express a fusion protein with a six-histidine tag, a thrombin recognition site and a T7 tag at the N-terminus. These additional amino acids increase the size of expressed protein to about $20 \mathrm{kDa}$. The recombinant pET32a (pET32a-CagA) is transformed into E. coli, BL21 (DE3) pLysS ( $f$ - ompthsdB, $r B-m B-, d c m$ gal, DE3, pLYsScmr). The required antibiotics were added to LB media according to the reference recommendation (7). All chemicals were purchased from Merck (Germany) and all of the enzymes were provided from Fermentas (Lithuania) or Cinagen (Iran).

Fifteen patients ( 8 male, 7 female) referred to the ValiAsr Hospital (a teaching university hospital in Arak, Iran) from May to October 2011 for diagnostic upper gastrointestinal (UGI) endoscopy, were prospectively enrolled in this study. Patients were considered H. pylori-positive when the results of RUT were positive. a5-10 cc blood sample was taken from each patient after red blood cell separation (3000 rpm for 5 minutes). Sera were collected and frozen at $-20^{\circ} \mathrm{C}$.

H. pylori was isolated from a biopsy sample of a dyspeptic patient undergoing endoscopy, who granted informed consent. Two biopsy samples were processed for cultivationona5\% packed cell Columbia agar containing 2-4\% fetal calf serum (Oxoid-Basingstoke, UK) and Skirrow's antibiotic supplements (Oxoid, UK). The plates were incubated at $37^{\circ} \mathrm{C}$ for 5-7 days in microaerophilic conditions. The isolates were identified as $H$. pylori by urease, catalase and oxidase reactions and Gram staining (8). Molecular identification was confirmed by PCR amplification of the conserved ureC gene of $H$. pylori as described (9).

Antigenic regions: To find out the antigenic region of CagA, the sequence of CagA gene (NCBI GenBank, gi: 259123369) was submitted to ABCpred, Bcepred and Emboss Antigenic web servers. Two specific Primers were designed base on the sequences with OLIGO5 software. The forward primer (5' TATGGATCCACAATAACGCTC 3') starts from the beginning of the gene and contain BamHI site.
Reverse primers (5'ATTCTCGAGTTCATCAAAAGATT 3') contain recognition site for $X h o I$. The restriction enzyme sites (underlined) were added to the primers for subsequent cloning procedure. These two primers were designed to amplify a 1245 bp fragment of the CagA coding region.

\subsection{Chromosomal DNA Isolation}

Genomic DNA was extracted from cultured samples according to the standard $\mathrm{CTAB} / \mathrm{NaCl} \operatorname{protocol}(7,10)$. Then, the pellet of $1.5 \mathrm{~mL}$ bacterial culture was resuspended overnight in TE buffer (Tris $10 \mathrm{mM}$, EDTA $1 \mathrm{mM}$, and $\mathrm{pH} 8$ ), the bacterial cell was lysed by sodium dodecyl sulphate (SDS 10\%) and proteinase $\mathrm{K}(20 \mathrm{mg} / \mathrm{mL})$, the chromosomal DNA was extracted by $\mathrm{CTAB} / \mathrm{NaCl}$ solution $(10 \% \mathrm{CTAB}$ and $0.7 \mathrm{M} \mathrm{NaCl}$ ). Cell debris and proteins were removed by mixing and genomic DNA was extracted with two times washing with phenol/chloroform/isoamylalcohole (25:24:1) mixture. The tubes were centrifuged at 10000 rpm for 10 minutes at $4^{\circ} \mathrm{C}$ and the supernatants were transferred to a fresh tube. In this phase, protein was deposited and RNA and DNA remained in aqueous solution. DNA was precipitated by isopropanol and washed with 70\% ethanol and dissolved in TE buffer and stored at $-20^{\circ} \mathrm{C}$.

\subsection{Gene Amplification}

PCR was performed in a $50 \mu \mathrm{L}$ total volume containing $500 \mathrm{ng}$ of template DNA, $1 \mu \mathrm{M}$ of each primer, $2.5 \mathrm{mM}$ $\mathrm{Mg}^{2+}, 200 \mu \mathrm{M}$ (each) deoxynucleoside triphosphates, $1 \times$ PCR buffer and 2.5 unit of pfu DNA polymerase (Fermentas, Lithuania). The following conditions were used for amplification: hot start at $94^{\circ} \mathrm{C}$ for five minutes, followed by thirty cycles of denaturation at $94^{\circ} \mathrm{C}$ for one minute, annealing at $50^{\circ} \mathrm{C}$ for one minute and extension at $72^{\circ} \mathrm{C}$ for one minute. The program followed by a final extension at $72^{\circ} \mathrm{C}$ for five minutes. The PCR product was analyzed by electrophoresis in $1 \%$ agarose gel in $1 \times$ TBE buffer and visualized by ethidiuethidium bromide staining on UV transilluminator (11).

\subsection{Cloning of arCagA Gene in Bacterial Expres- sion Vector}

The PCR product was purified from the agarose gel with high pure PCR product purification kit (Roche, Germany) .The PCR product was digested with BamHI and XhoI and ligated to pET32a, which were digested by the same restriction enzymes, using T4 DNA ligase at $16^{\circ} \mathrm{C}$ overnight. Moreover Escherichia coli DH5 $\alpha$ and E. coli BL21 (DE3) pLYsS competent cells were prepared by calcium chloride method and were used for transformation of plasmid (7).

\subsection{Expression and Purification of Recombinant $\operatorname{Cag} A$}

The pET32a-arCagA plasmids was transformed into $E$. 
Farjadi Vet al.

coli BL21 (DE3) pLYsS according to the standard method (7) and grown on2 mL Luria Bertani (LB) Broth supplemented with Ampicillin $(100 \mu \mathrm{g} / \mathrm{mL})$ at $37^{\circ} \mathrm{C}$ with agitation. A colony containing the recombinant plasmid was incubated on shaking incubator for overnight at $37^{\circ} \mathrm{C}$ in $2 \mathrm{~mL}$ LB medium containing $100 \mu \mathrm{g} / \mathrm{mL}$ Ampicillin. For expression of recombinant protein, $500 \mu$ Lof culture was added in $50 \mathrm{Ml} \mathrm{LB}$ broth (per liter contains: $10 \mathrm{~g}$ yeast extract (Difco, USA), $20 \mathrm{~g}$ Bacto tryptone broth (Difco, USA), $0.2 \%$ (mass/vol) glucose, $10 \mathrm{~g} \mathrm{NaCl}, 1 \mathrm{~g} \mathrm{KCl}, 0.5 \mathrm{~g} \mathrm{MgCl}$, $0.5 \mathrm{~g} \mathrm{CaCl}_{2}, 100 \mu \mathrm{g} / \mathrm{mL}$ Ampicillin), incubated at $37^{\circ} \mathrm{C}$ and $200 \mathrm{rpm}$ shaking with vigorous agitation until the optical density reached 0.6 at $600 \mathrm{~nm}$. Expression of the CagA protein was then induced by the addition of Isopropyl thio $\beta$-D-galactosidase (IPTG) to a final concentration of 1 $\mathrm{mM}$ and incubation was continued for the next 4 hours.

The expressed protein was purified by Ni-NTA agarose resin affinity chromatography according to manufacture instruction (Qiagen, USA). The quality and quantity of purified recombinant arCagA protein was analyzed by SDS polyacrylamide gel electrophoresis (SDS-PAGE 12\%) and Bradford methods, respectively (7). In order to analyze the cross-reaction between fused segments ( $20 \mathrm{kDa})$ of recombinant arCagA protein (in pET32a) with patient sera, an E. coli BL21 (DE3) plysS containing pET32 a vector was induced by IPTG as a control.

\subsection{Antigenicity of Recombinant arCagA}

The integrity of the product was confirmed by westernblot analysis. Serum from an $H$. pylori sero-positive patient (1:100 dilution), CagA antibody and normal human sera were used as primary antibody. Western blotting was performed according to standard protocol (12) using normal human sera and CagA antibody as negative and positive control, respectively. For western blot analyses, $0.5 \mu \mathrm{g}$ purified recombinant arCagA protein was used per well. The gel was blotted on to poly vinylidinedifluoride (PVDF) Membrane (Roche, Germany) using transfer buffer containing 25 mMTris ( $\mathrm{pH}=8.3), 192 \mathrm{mM}$ glycine and $20 \%$ methanol at 90 Vfor 3 hours at $4{ }^{\circ} \mathrm{C}$. The blotted membrane was blocked with $2.5 \%(\mathrm{w} / \mathrm{v})$ BSA in TBS buffer (0.5 M NaCl, $0.02 \mathrm{M}$ Tris pH 8.5, 0.05\% tween 20) for 1 hour at room temperature. Membranes were incubated for 2 hours at room temperature with diluted sera 1:100 from patient's sera, normal sera and CagA antibody. After reaction with the primary antibody, the membranes were washed three times with TBS and incubated with antihuman IgG (Bioscience, USA) in 1:1000 dilution of TBS.

Then washed three times with TBS and reactions were developed by Diamino Banzidine (DAB) solution (Roche, Germany). As a negative control, the bacterial lysate from induced E. coli BL21 (DE3) pLysS containing pET32a vector was analyzed by Western blot.

\section{Results}

\subsection{Antigenic Regions}

According to the results of three data banks which were in accordance, amino acids sequence of 886 till 2131 was selected as regions with high antigenic properties (Figure 1).

Y GS T I T L Y L L C W GVHS I EPEKV S L Y GDNG GPEARHD W NAT V GYK DQ Q GSNVA T L I A H L Y GS GLIIA GNEDGIKNPS F Y L Y E D Q L T G L K A MSQEEI Q NKVDFLEFLAKNNAKLDNLSEKEKEKF Q T I ENFQKDRKA YLD A L G D H V A F V S K D Q K H L A L I T F G G EVS Y T L KD Y GK Q K K L D GEVKT T L Q GSLKYD GMMFVDYSNFKYT NAS S P K GVSAT N G S H L E A N F S K A V F N L P N L N L A I T Y IRRD L E K L W A K GL S P Q A N K L IKD FLNSNKELVVKVSNFNKAVAEAKNT GNYDEVKKA Q KD L EKSLRKREH L E K E V A K K L E S R I N K N R E A K A Q A N Q K D K I F A L I K E A S K E A R A A F D P N L K G I R S L S D K L E N I K N L K D F G K S F D E L N

Figure 1. The Result of Antigenic Fragments

\subsection{DNA Amplification and Molecular Charac- terization of arCagA Gene}

The chromosomal DNA of H. pylori was extracted for amplification of $\operatorname{arCagA}$ gene. The amplified fragment had the expected size of 1245 bp comparing to $100 \mathrm{bp}$ DNA ladder (Fermentas, Lithuania).

\subsection{PCR Product Analysis and Cloning}

The recombinant plasmid (pET32a-arCagA) was sequenced by standard primers and dideoxy chain ter- mination method (Figure 2).

The sequencing result was confirmed by comparing databases and using basic local alignment search tool (BLAST) software (data not shown). Data showed that, PCR product was identical to CagA gene (NCBI GenBank, gi: 259123369). To confirm the transformation of pET32a-arCagA into E.coliBL21(DE3) pLYsS, PCR reaction and enzymatic digestion with BamHI and XhoI were performed and showed that the target gene was inserted correctly into it. 


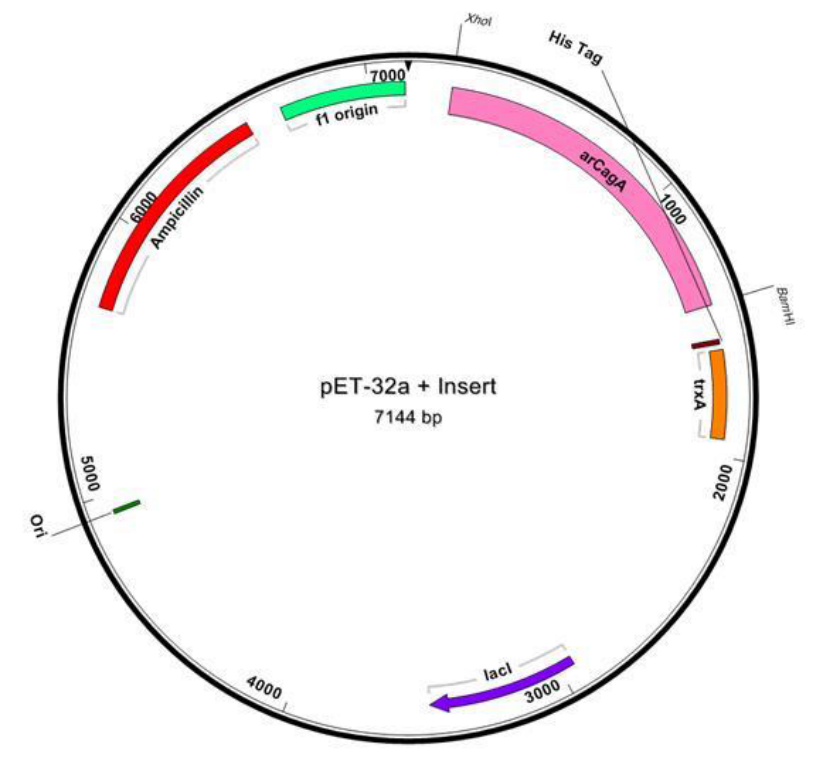

Figure 2. Schematic Representation of the PET32a and rCaga

\subsection{Expression and Purification of Recombinant Protein}

pET32a-arCagA which was constructed by insertion of 1245 bp fragment of CagA gene (encoding a $\sim 66 \mathrm{kDa}$ mature peptide) into the pET32a (expression vector) was introduced into E.coli BL21 (DE3) pLYsS and the expression of recombinant protein was induced by IPTG. SDS-PAGE analysis of induced cells showed a band with desired molecular weight of $65 \mathrm{kDa}$. Due to the presence of $6 \mathrm{x}$ His-tag at the N-terminal region of $\operatorname{arCagA}$, we could purify the recombinant protein using Ni-NTA resin affinity chromatography (Figure 3 ) and we obtained $13 \%$ purity of arCagA expressed protein in E. coli . The concentration of recombinant protein was assayed after purification and calculated to $470 \mathrm{mg} / \mathrm{L}$ of the initial culture.

\subsection{Immunoblotting Analysis in Infected Human}

To determine the antigenicity of recombinant antigenic region of CagA protein in patients' sera, identity confirmation of antigenic region r-CagA was performed via Western blotting and the desired band was observed with an estimated molecular weight to f $65 \mathrm{kDa}$. Figure 4 shows the specific interaction between patients' serum, human normal sera and CagA antibody with purified recombinant arCagA protein. Human normal sera were used as a negative control and CagA antibody used as a positive control.

There was no reaction between the expressed pET32a in E. coli BL21 (DE3) pLysS and patient serum (data notshown).
Figure 3. Expression of Recombinant Antigenic Fragment of CagA Protein and It's Purification.

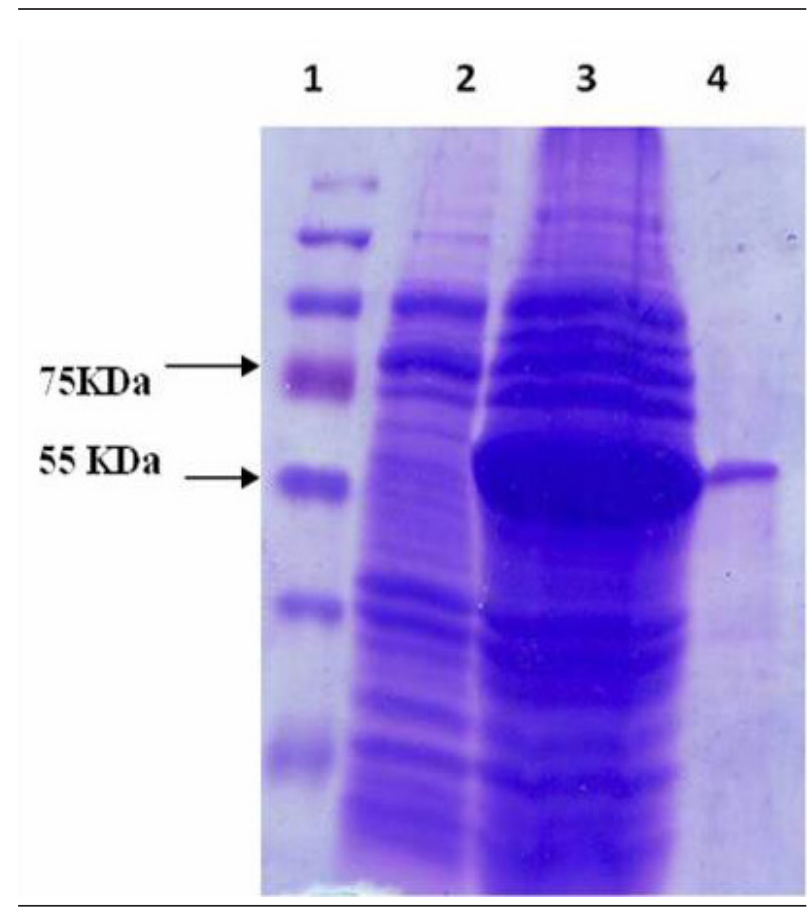

Lane 1: Protein marker (Fermentas, Lithuania), Lane 2 : pET32a-CagA before induction, Lane 3: pET32a-CagA after 4 hours induction, Lane 4 : purification of recombinant fragment of CagA protein.

Figure 4. Western Blot Analysis of CagA Recombinant Antigenic Fragment Using Patient Sera.

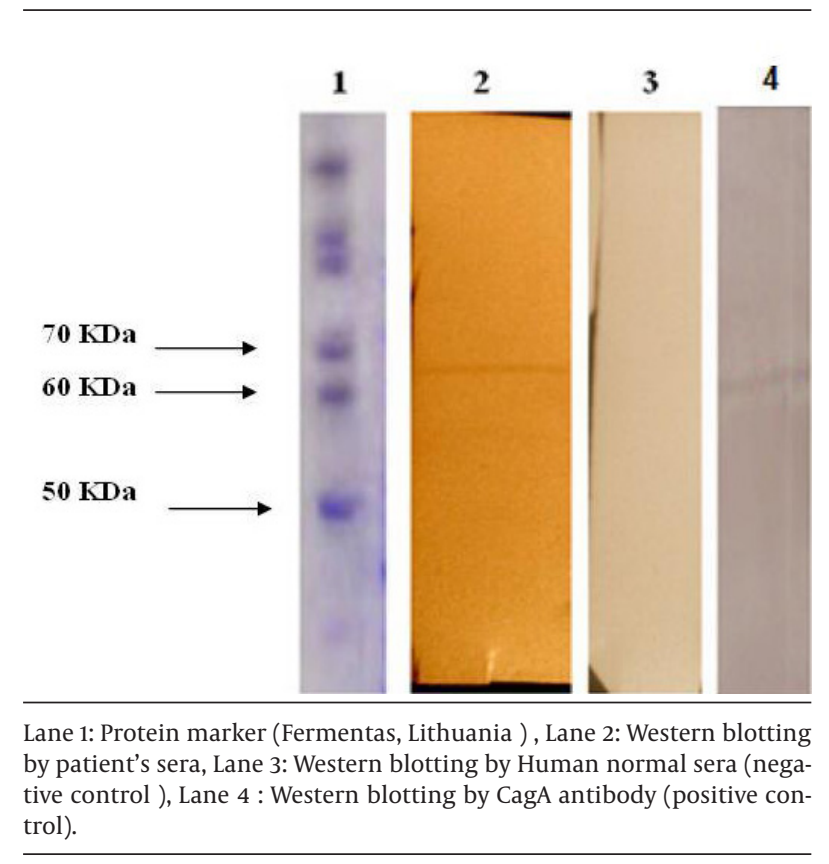


Farjadi Vet al.

\section{Discussion}

In this study, we have shown that recombinant antigenic region of CagA (arCagA) protein can be produced by the means of pET32a in E. coli. Our findings showed that antigenic protein of CagA of H.pylori could be detected by human sera infected with $H$. pylori. The discovery of $H$. pylori in 1982 was the starting point of a revolution concerning the concepts and management of gastroduodenal diseases. It is now well accepted that the most common stomach diseases, peptic ulcer diseases, are infectious diseases and all consensus conferences agree that the causative agent, $H$. pylori infection, must be treated with antibiotics. Furthermore, this possibility that bacterium could be the trigger of various malignant diseases of the stomach has been emerged and it is now a model for chronic bacterial infections causing cancer (13).

H. pylori infection can be diagnosed by invasive and noninvasive tests. Serological testing can be performed on noninvasive collected clinical samples. Serological detection of infection caused by $H$. pylori containinga CagAby the use of anti-CagA ELISA and Western blot of CagA are the only noninvasive diagnostic tests at present available for assessing strain virulence potential and possible disease risk. The reliability of CagA serology as a predictive test for determining the CagA genotype of the infecting strain is important because various serological assays are now available (14).

Many strains of $H$. pylori produce CagA, which is an immunogenic high molecular weight protein (120-145 kDa protein) that induces numerous alterations in cellular signaling pathways, leading to the designation of CagA as a "bacterial on coprotein" ( 15 ). H. pylori CagA+ strains have been associated with gastric ulcers, duodenal ulcers and gastric cancers ( 16 ). Thus this protein can be a strong vaccine candidate against $H$. pylori infections. Production of recombinant CagA has been already done by the Tummuru ( 17 ), but due to heavy molecular weight (120 KD), the protein was degraded. Hence in this study, the part of CagA protein with suitable antigenic properties which had been determined with bioinformatics methods, was used for detecting antibody. Therefore the protein obtained in this study is much smaller than normal CagA protein, presenting the same antigenic properties. This recombinant CagA can be used for detecting CagA antibody. By expression of protein in pET32a, several amino acids such as thioredoxin protein , 6xHis tag and T7 tag are added to the $\mathrm{C}$ or $\mathrm{N}$ terminal of recombinant peptide. These additional amino acids may leaded to an about $20 \mathrm{kDa}$ increase of the synthesized peptide molecular weight, as shown in Figure 3, which can be interfered with the subsequent immunological analyses.

In order to investigate the effect of additional amino acids (thioredoxin protein, 6xHis tag and T7 tag) pET32a vector in E. coli [BL21 (DE3) pLysS] was also induced by IPTG and further Western blotting on human sera was performed. The results showed that there was no inter- fere related to fused amino acids.

In this study, we used E. coli BL21 (DE3) plysS; this strain has deficient in the cytoplasmic protease gene products including Lon, OmpT, DegP or HtpR, in order to produce high expression level of fusion proteins. Therefore the highest expression of recombinant CagA in E. coli BL21 (DE3) plys could be due to protease deficiency in this strain. The pET system has been recognized as one of the most powerful methods for producing recombinant proteins in E. coli and the significant advantages of this system have been widely discussed. All pET vectors are available in three reading frames. The plasmid contains the f1 origin of replication and the T7 lac promoter using IPTG as the inducer (10).

Our findings also indicate that the highly regulated expression vector with powerful T7 promoter (pET32a,), in conjunction with suitable host cell E. coli, BL21 (DE3) pLysS, could influence the expression level. The expressed protein in pET system containing 6xHis tag is linked to either $\mathrm{C}$ or $\mathrm{N}$ terminal extension of protein for purification through an immobilized metal affinity chromatography (IMAC). Another advantage of using pET32a is the presence of fusion tag at N-terminal of the multiple cloning sites (MCS) which provides stability for RNA polymerase during transcription of the cloned gene.

In this study, we have cloned and expressed antigenic region of CagA under the control of T7 promoter in optimized condition. Present data showed that recombinant antigenic region of CagA is known as an antigen by patients' immune system. Therefore, recombinant antigenic region of CagA protein has same epitopes with natural form of this antigen. Recombinant antigenic region CagA also seemed to be a promising antigen for the serologic diagnosis of $H$. pylori infections.

Data indicates that antigenic parts of H. pylori recombinant CagA protein were recognized by human immunity system of infected individual. It can be concluded that antigenic regions of CagA have antigenic property that can be further used for the development of $H$. pylori vaccine, ELISA kits and diagnostic purpose.

\section{Acknowledgements}

The present study was supported by Arak University of Medical Sciences.

\section{Authors' Contribution}

All authors had equal contribution.

\section{Financial Disclosure}

None declared.

\section{Funding/Support}

This study was supported by Arak University of Medical Sciences. 


\section{References}

1. Suerbaum S, Michetti P. Helicobacter pylori infection. $N$ Engl J Med. 2002;347(15):1175-86.

2. Vaira Dino, Malfertheiner Peter, Megraud Francis, Axon Anthony TR, Deltenre Michel, Hirschl Alexander M, et al. Diagnosis of Helicobacter pylori infection with a new non-in vasive antigen-based assay. The Lancet. 1999;354(9172):30-33.

3. Backert S, Selbach M. Role of type IV secretion in Helicobacter pylori pathogenesis. Cell Microbiol. 2008;10(8):1573-81.

4. Leite KR, Darini E, Canavez FC, Carvalho CM, Mitteldorf CA, Camara-Lopes LH. Helicobacter pylori and cagA gene detected by polymerase chain reaction in gastric biopsies: correlation with histological findings, proliferation and apoptosis. Sao Paulo Med J. 2005;123(3):113-8.

5. Marshall B. Helicobacter pylori: 20 years on. Clin Med. 2002;2(2):147-52.

6. Diomedi M, Pietroiusti A, Silvestrini M, Rizzato B, Cupini LM, Ferrante $\mathrm{F}$, et al. CagA-positive Helicobacter pylori strains may influence the natural history of atherosclerotic stroke. Neurology. 2004;63(5):800-4.

7. Sambrook Joseph, Russell David W. Molecular cloning: a laboratory manual (3-volume set). 3 edNew York: Cold Spring Harbor Laboratory Press; 2001.

8. Radcliff FJ, Hazell SL, Kolesnikow T, Doidge C, Lee A. Catalase, a novel antigen for Helicobacter pylori vaccination. Infect Immun. 1997;65(11):4668-74.
9. Labigne A, Cussac V, Courcoux P. Shuttle cloning and nucleotide sequences of Helicobacter pylori genes responsible for urease activity. J Bacteriol.1991;173(6):1920-31.

10. Mahmoudi S, Abtahi H, Bahador A, Mosayebi G, Salmanian AH Production of recombinant streptokinase in E. coli and reactivity with immunized mice. PakJ Biol Sci. 2010;13(8):380-4.

11. Mc Pherson MJ, Moller SG. PCR, The basic from background to bench.Oxford, UK: BIOS Scientific Publishers Ltd; 2000.

12. Ausubel Frederick M. Current protocols in molecular biology:: J. Wiley; 1987.

13. Megraud F, Lehours P. Helicobacter pylori detection and antimicrobial susceptibility testing. Clin Microbiol Rev. 2007;20(2):280322.

14. Saffari M, Abtahi H. Comparison between invasive and noninvasive tests in diagnosis of Helicobacter pylori infection. PakJ Biol Sci. 2010;13(10):509.

15. Hatakeyama M. Oncogenic mechanisms of the Helicobacter pylori CagA protein. Nat Rev Cancer. 2004;4(9):688-94.

16. Figueiredo C, Van Doorn LJ, Nogueira C, Soares JM, Pinho C Figueira $\mathrm{P}$, et al. Helicobacter pylori genotypes are associated with clinical outcome in Portuguese patients and show a high prevalence of infections with multiple strains. Scand J Gastroenterol. 2001;36(2):128-35.

17. Tummuru MK, Cover TL, Blaser MJ. Cloning and expression of a high-molecular-mass major antigen of Helicobacter pylori: evidence of linkage to cytotoxin production. Infect Immun. 1993;61(5):1799-809. 